This item was submitted to Loughborough's Research Repository by the author.

Items in Figshare are protected by copyright, with all rights reserved, unless otherwise indicated.

\title{
Anodized steel electrodes for supercapacitors
}

PLEASE CITE THE PUBLISHED VERSION

http://dx.doi.org/10.1021/acsami.5b12107

PUBLISHER

(c) American Chemical Society

VERSION

VoR (Version of Record)

\section{PUBLISHER STATEMENT}

This work is made available according to the conditions of the Creative Commons Attribution 4.0 International (CC BY 4.0) licence. Full details of this licence are available at: http://creativecommons.org/licenses/ by/4.0/

\section{LICENCE}

CC BY 4.0

\section{REPOSITORY RECORD}

Sagu, Jagdeep, Upul Wijayantha-Kahagala-Gamage, Mallika Bohm, Siva Bohm, and Tapan Kumar Rout. 2019. "Anodized Steel Electrodes for Supercapacitors". figshare. https://hdl.handle.net/2134/20780. 


\title{
Anodized Steel Electrodes for Supercapacitors
}

\author{
Jagdeep S. Sagu, ${ }^{\dagger}$ K. G. Upul Wijayantha, ${ }^{* \dagger}{ }^{\dagger}$ Mallika Bohm, ${ }^{\ddagger}$ Siva Bohm, ${ }^{\ddagger}$ and Tapan Kumar Rout ${ }^{\S}$ \\ ${ }^{\dagger}$ Energy Research Laboratory (ERL), Department of Chemistry, Loughborough University, Loughborough LE11 3TU, United \\ Kingdom \\ ${ }^{\ddagger}$ Swinden Technology Centre, TATA Steel R\&D, Moorgate, Rotherham S60 3AR, United Kingdom \\ ${ }^{\S}$ New Technology Developments \& Strategy Planning Research \& Development Division, TATA Steel Ltd., Jamshedpur 831007, \\ India
}

Supporting Information

ABSTRACT: Steel was anodized in $10 \mathrm{M} \mathrm{NaOH}$ to enhance its surface texture and internal surface area for application as an electrode in supercapacitors. A mechanism was proposed for the anodization process. Field-emission gun scanning electron microscopy (FEGSEM) studies of anodized steel revealed that it contains a highly porous sponge like structure ideal for supercapacitor electrodes. X-ray photoelectron spectroscopy (XPS) measurements showed that the surface of the anodized steel was $\mathrm{Fe}_{2} \mathrm{O}_{3}$, whereas X-ray diffraction (XRD) measurements indicated that the bulk remained as metallic Fe. The

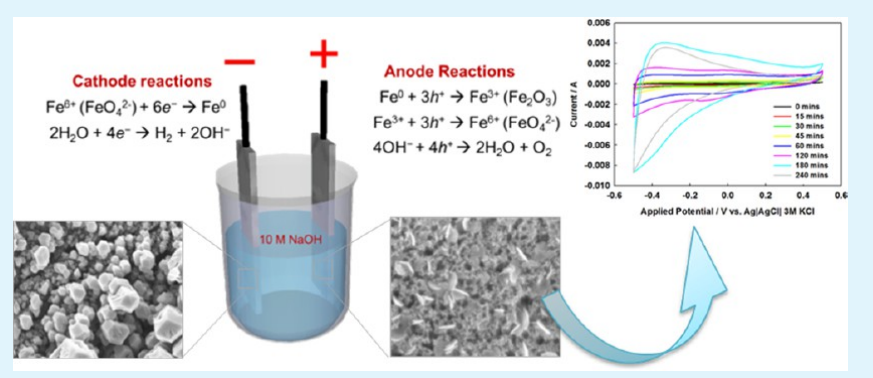
supercapacitor performance of the anodized steel was tested in $1 \mathrm{M} \mathrm{NaOH}$ and a capacitance of $18 \mathrm{mF} \mathrm{cm}^{-2}$ was obtained. Cyclic voltammetry measurements showed that there was a large psueudocapacitive contribution which was due to oxidation of $\mathrm{Fe}$ to $\mathrm{Fe}(\mathrm{OH})_{2}$ and then further oxidation to $\mathrm{FeOOH}$, and the respective reduction of these species back to metallic Fe. These redox processes were found to be remarkably reversible as the electrode showed no loss in capacitance after 10000 cycles. The results demonstrate that anodization of steel is a suitable method to produce high-surface-area electrodes for supercapacitors with excellent cycling lifetime.

KEYWORDS: anodization, steel, nanostructure, supercapacitor, electrode, iron oxide

\section{INTRODUCTION}

High surface area with regular pore size and distribution, high conductivity, stability, and a large enough potential window are the desired properties for a prospective active material for use in supercapacitor electrodes. The most commonly used material in commercially available supercapacitors is carbon, in its many forms, such as CNTs, activated carbons, and more recently, graphene, as all these forms possess the key desired properties. The high-surface-area active material is usually supported by a conducting substrate/current collector (such as nickel foam, aluminum foil, silver or copper), ${ }^{1-4}$ although, there are some recent reports of substrate/current collector free supercapacitors. $^{5-9}$ The reported substrate/current collector free supercapacitors are lab scale, and material handling issues such as brittleness are the main obstacles for manufacturing them at large scale. If a substrate/current collector is to be used, the high surface area active material (i.e., carbon and other desired forms of it) must have good electrical contact and adhesion to it, especially as heavy duty supercapacitors often use coiled up electrodes. Typically polymeric binders are used with activated carbons in order to facilitate adherence to the current collectors. ${ }^{10}$ However, addition of binders is known to be detrimental to the electrodes performance, as it can reduce the surface area and dramatically decrease the electrode's conductivity. Poor adhesion can also be a source of high contact resistance between the high surface area active material and the substrate/current collector, which then contributes to the overall series resistance. It is also widely known that adhesion (provided by binders) becomes weak over prolong use/cycling of supercapacitors in liquid electrolytes. For these reasons, new advances that enable to overcome these drawbacks are a hot area of supercapacitor research.

As current collectors are metallic, depending on the potential window of supercapacitor, they can undergo electrochemical reactions which have various degrees of reversibility, unless they are shielded by the active material to prevent direct contact with the electrolyte, thus it can be unstable for a large number of charge/discharge cycles. However, if the reversibility is good, it could be ideal for a pseudocapacitor, where the majority of the charge storage comes from faradaic charge transfer between the electrode and the electrolyte. If such current collector is identified, the overall capacitance can be further enhanced by increasing the surface area of the current collector (by nanostructuring) and adding a larger double-layer component to the capacitance. Nanostructuring has been achieved by many different methods. While chemical etching can be used to

Received: December 11, 2015

Accepted: February 18, 2016

Published: February 18, 2016 
increase the surface area, its effect is more of a conformal nature; thus it is difficult to control and produce highly porous structures required for supercapacitors. Anodization is an alternative top-down approach, which is a commonly used electrolytic method for surface texturing metals. In fact, it is well-known that anodization of metals improves adhesion of anticorrosion primer coatings. The formation of nanostructures by anodization has been well reported for many metals, such as $\mathrm{Al},{ }^{11} \mathrm{Ti}^{12}{ }^{12} \mathrm{Hf},{ }^{13} \mathrm{Zn},{ }^{14} \mathrm{Ni},{ }^{15} \mathrm{Nb},{ }^{16} \mathrm{~W},{ }^{17}$ as well as Fe. ${ }^{18}$

In this paper, the anodization of plain steel was conducted in order to create large surface area nanostructures so they could be used as supercapacitor electrodes. As steel consists mainly of $\mathrm{Fe}$, similar protocols to those reported in the literature for $\mathrm{Fe}$ anodization could be adopted. There are a number of reports in the literature for the anodization of $\mathrm{Fe}$, but all of these methods make use of $\mathrm{NH}_{4} \mathrm{~F}$ as the electrolyte in glycol. ${ }^{18-25}$ Parameters such as potential, temperature, anodization time, and $\mathrm{NH}_{4} \mathrm{~F}$ concentration have been varied in order to control the nanostructure of $\mathrm{Fe}$. As the anodization process results in a porous nanostructure, it is logical to assume that two processes are occurring: (i) oxidation of $\mathrm{Fe}(0)$ to $\mathrm{Fe}(\mathrm{III})$ and (ii) the dissolution of $\mathrm{Fe}(\mathrm{III})$ species in to the electrolyte. For the $\mathrm{NH}_{4} \mathrm{~F}$ electrolyte, the following mechanism has been proposed in the literature $18,19,21,24$

$$
\begin{aligned}
& 2 \mathrm{Fe}+3 \mathrm{H}_{2} \mathrm{O} \rightarrow \mathrm{Fe}_{2} \mathrm{O}_{3}+3 \mathrm{H}_{2} \\
& \mathrm{Fe}_{2} \mathrm{O}_{3}+12 \mathrm{~F}^{-}+6 \mathrm{H}^{+} \rightarrow 2\left[\mathrm{FeF}_{6}\right]^{3-}+3 \mathrm{H}_{2} \mathrm{O}
\end{aligned}
$$

In this mechanism, it is the dissolution of $\mathrm{Fe}_{2} \mathrm{O}_{3}$ by the fluoride ion that results in the nanostructure. The majority of applications investigated to date of anodized $\mathrm{Fe}$ have been limited to use as a photoanode to drive photoelectrochemical reactions, ${ }^{18,20-22,24,25}$ (i.e., $\mathrm{Fe}_{2} \mathrm{O}_{3}$ as an n-type semiconductor electrode for photoelectrolysis). In the present work, aqueous $\mathrm{NaOH}$ is used as the electrolyte for anodization. ${ }^{26}$ The method can be easily scaled up without need of special chemical treatments or facilities (i.e., to handle $\mathrm{NH}_{4} \mathrm{~F}$ ). A mechanism is proposed for the anodization of steel in $\mathrm{NaOH}$. The supercapacitor performance of the anodized steel was evaluated in $1 \mathrm{M} \mathrm{NaOH}$ and a capacitance of $18 \mathrm{mF} \mathrm{cm} \mathrm{cm}^{-2}$ with series resistances as low as 2 ohms was obtained. Furthermore, to best of our knowledge there are no reports published for the use of anodized steel (or $\mathrm{Fe}$ ) in supercapacitors. The results demonstrate that the anodized steel is ideal for use as the negative electrode in an asymmetric supercapacitor.

\section{EXPERIMENTAL SECTION}

Sample Preparation by Anodization. The cold rolled steel substrates (Q-panel) were cut in to $25 \times 50 \mathrm{~mm}$ strips and were ultrasonically cleaned in isopropanol and acetone for $15 \mathrm{~min}$ prior to anodization. Two steel strips were immersed $(45 \mathrm{~mm})$ in to a beaker containing $10 \mathrm{M} \mathrm{NaOH}$. The steel strips were connected to the negative and positive terminals of a DC power supply. The anodization time was systematically varied from 15 to $240 \mathrm{~min}$. The initial voltage and current readings were $3.7 \mathrm{~V}$ and $1.5 \mathrm{~A}$, respectively, however, these values varied over the course of anodization. During the anodization bubbles were produced on each electrode, which corresponded to oxygen and hydrogen evolution on the respective electrodes. Nanostructuring occurs on the anode, while at the cathode a gray/black deposit was seen, and this coating was characterized to ascertain the anodization mechanism. After the anodization was completed, the power supply was turned off and the nanostructured steel electrode (anode) was removed and washed several times with deionized water and ethanol and dried.
Sample Characterization. The anodized steel samples were characterized using a Leo 1530 VP field emission gun scanning electron microscope (FEGSEM) at an accelerating voltage of $5 \mathrm{kV}$ and a working distance of $5 \mathrm{~mm}$. The phase and crystallinity of the films were characterized using a Bruker AXS Advance X-ray diffractometer with primary monochromatic high intensity $\mathrm{Cu} \mathrm{K} \alpha(\lambda=1.541 \AA)$ radiation. XPS measurements were conducted using Thermo Scientific (model K-Alpha) spectrometer. Raman spectra were collected using a HORIBA Jobin Yvon LabRAMHR (with a $632.8 \mathrm{~nm} \mathrm{He-Ne} \mathrm{laser)}$ Raman spectrophotometer.

Electrochemical Characterization. The electrochemical properties of the nanostructured steel were evaluated in aqueous $1 \mathrm{M} \mathrm{NaOH}$ in a three-electrode electrochemical cell with a $\mathrm{Ag} \mid \mathrm{AgCl} 3 \mathrm{M} \mathrm{KCl}$ reference electrode, and a platinum gauze counter electrode. The potential of the electrode was controlled using a potentiostat (PGSTAT12). Cyclic voltammetry was carried out in a standard 3electrode electrochemical cell in $1 \mathrm{M} \mathrm{NaOH}$ between -0.5 to $0.5 \mathrm{~V}$ against $\mathrm{Ag} \mid \mathrm{AgCl} 3 \mathrm{M}$ KClusing $\mathrm{Ag} \mid \mathrm{AgCll} 3 \mathrm{M} \mathrm{KCl}$ and $\mathrm{Pt}$ as the reference and counter electrode, respectively. Impedance measurements were carried out at open-circuit potential at a frequency range of $0.01 \mathrm{~Hz}$ to $1 \mathrm{MHz}$

\section{RESULTS AND DISCUSSION}

Materials Characterization. Cold-rolled steel strips were anodized in $10 \mathrm{M} \mathrm{NaOH}$ for various time intervals as specified; the appearance of the samples anodized for different time intervals can be seen in the Figure S1. For relatively shorter anodization times (i.e., 15 to $120 \mathrm{~min}$ ), the anodized layer showed colorful fringes, whereas for longer anodization times (i.e., 180 and $240 \mathrm{~min}$ ), the color became increasingly red, indicating that the surface may have been oxidized to $\mathrm{Fe}_{2} \mathrm{O}_{3}$, which has a characteristic red color. Anodization was not continued longer than $240 \mathrm{~min}$ because beyond this point, the anodized layer started to crumble and became mechanically unstable and was easily rubbed off. During the anodization process, bubbles were seen on both the cathode and the anode, which corresponded to water reduction and oxidation to hydrogen and oxygen, respectively. The voltage and current at the start of anodization was around $3.7 \mathrm{~V}$ and $1.5 \mathrm{~A}$, respectively, both of which decreased throughout the course of the experiment. As the power supply was an analogue device, it was not possible to monitor and record the voltage and current with respect to time in order to determine the overall charge passed during the anodization process. Also, as the faradaic efficiency of the process was unknown, a better method to track the progress of the reaction was by monitoring the mass difference in the steel electrode before and after the anodization process. A plot of mass difference as a function of anodization time is shown in Figure S3.

During the anodization process, it was observed that the electrolyte solution $(10 \mathrm{M} \mathrm{NaOH})$ gradually turned purple. About 2 to $3 \mathrm{~mL}$ of this purple colored electrolyte solution was collected at the end of each anodization in sample vials (see the Figure S2). The solution was clear and purple, indicating that the species in the solution were completely dissolved. The vials were left in a cupboard in the dark, and after 1 week it was found that precipitation of a red/brown solid occurred, resulting in a clear colorless solution above the settled solid. A Pourbaix diagram (see ref 27) was used as a guide to identify the purple colored species in the electrolyte solution. ${ }^{27}$ The $\mathrm{pH}$ of the $10 \mathrm{M} \mathrm{NaOH}$ electrolyte was estimated to be about $\mathrm{pH}$ 14.67. As a reference electrode was not used in the anodization process, the exact potential was difficult to track. The rapid oxygen evolution on the anode suggests that the electrode potential is well above $1.23 \mathrm{~V}$ (vs SHE). As guided by the 
Pourbaix diagram for $\mathrm{Fe}^{27}$ the dissolved species which have been etched away from the steel is most likely to be the ferrate(VI) ion, $\mathrm{FeO}_{4}{ }^{2-}$, which indeed has a characteristic purple color. ${ }^{28,29}$ The ferrate(VI) ion is the strongest watersoluble oxidizing agent, however it is not very stable in acidic or neutral $\mathrm{pH}$, but it can last for $8-9 \mathrm{~h}$ in alkaline solutions. ${ }^{30}$ After this period, it usually degrades back to $\mathrm{Fe}(\mathrm{III}) .^{30}$ This can account for the observations made in our study, in which the purple color in the solution disappeared resulting in a brown/ red precipitate at the bottom of vial, which is most likely a $\mathrm{Fe}(\mathrm{III})$ salt.

The surface morphology of the anodized steel was investigated using FEGSEM. The SEM images of steel anodized for 30 and $240 \mathrm{~min}$ are shown in Figures 1 and 2,
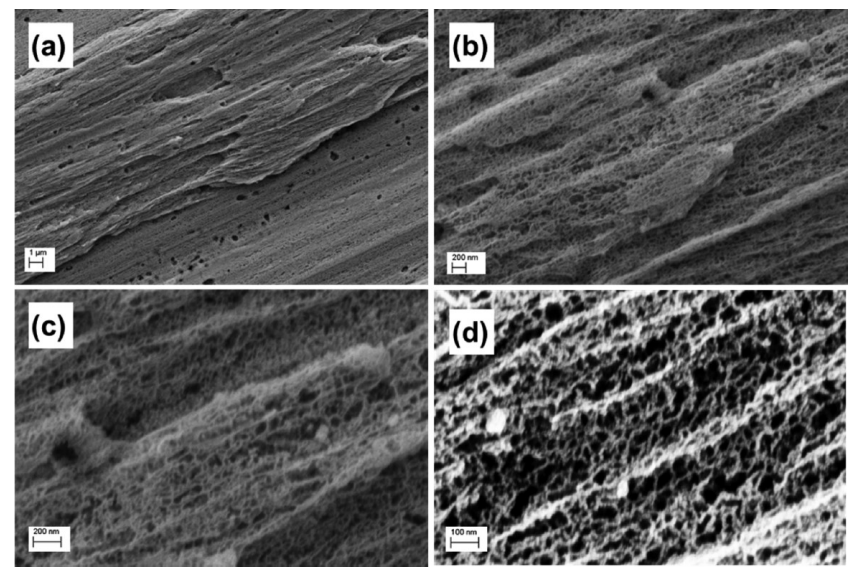

Figure 1. SEM images of nanostructured steel which has been anodized for $30 \mathrm{~min}$ at various magnifications of (a) $10 \mathrm{k} \mathrm{X}$, (b) $50 \mathrm{k} \mathrm{X}$, (c) $100 \mathrm{k} \mathrm{X}$, and (d) $200 \mathrm{k} \mathrm{X}$.

respectively, for various magnifications. From Figure 1, it can be seen that for an anodization time of $30 \mathrm{~min}$, the surface has a randomly orientated nanowire like morphology with an average pore sizes of around $50 \mathrm{~nm}$. For the longer anodization time of $240 \mathrm{~min}$ (Figure 2), the anodized surface adopts a more "sponge" like morphology. Cracks in the nanostructure are also visible, which may indicate the loss of mechanical strength of porous phase in certain parts of the electrode.

The XRD patterns were measured for plain steel as well as for each different time interval of anodization, as shown in Figure 3. The two peaks seen at 45 and $66^{\circ}$ correspond to the [110] and [200] reflections of cubic metallic Fe, respectively (ICDD 00-001-1262). As the anodization time was increased from 15 to $240 \mathrm{~min}$, the intensity of the [110] reflection gradually decreased. However, there appears to be no such trend for the [200] reflection. The decrease in the intensity of the [110] reflection with the increase of anodization time agrees with our observations in the electrolyte solution phase, as such that $\mathrm{Fe}$ is gradually being etched away or being oxidized to $\alpha-\mathrm{Fe}_{2} \mathrm{O}_{3}$. The absence of reflections for $\alpha-\mathrm{Fe}_{2} \mathrm{O}_{3}$ in the XRD indicates that either the bulk of the material is being retained as metallic $\mathrm{Fe}$ and oxidation has taken place purely on the surface, or that the $\alpha-\mathrm{Fe}_{2} \mathrm{O}_{3}$ is too amorphous to be detectable by XRD. If the latter is the case, evidence for the presence of $\alpha-\mathrm{Fe}_{2} \mathrm{O}_{3}$ should be available in the XPS analysis.

The high-resolution XPS spectra of the $\mathrm{Fe}$ and $\mathrm{O}$ regions of the $240 \mathrm{~min}$ anodized steel are shown in Figure $4 \mathrm{a}, \mathrm{b}$, respectively. In the Fe region, the peak at $724.9 \mathrm{eV}$ corresponds to $\mathrm{Fe}(\mathrm{III}) 2 \mathrm{p}_{1 / 2}$, and the peak at $711.2 \mathrm{eV}$ corresponds to $\mathrm{Fe}(\mathrm{III}) 2 \mathrm{p}_{3 / 2}$ with its associated satellite peak at $719.5 \mathrm{eV}$. These peaks are characteristic for hemeatite, $\alpha-\mathrm{Fe}_{2} \mathrm{O}_{3}{ }^{31}$ The XPS spectrum of the oxygen region shows the presence of two overlapping peaks. The peak at $530.1 \mathrm{eV}$ corresponds to $\mathrm{O} 1 \mathrm{~s}$, which is bound to $\mathrm{Fe}$ in the $\alpha-\mathrm{Fe}_{2} \mathrm{O}_{3}$. The smaller overlapping peak at 531.6 corresponds to $\mathrm{O} 1 \mathrm{~s}$ which corresponds to the oxygen contained in some organic impurities on the surface. Quantification of the $\mathrm{Fe}$ and $\mathrm{O}$ shows that the ratio between them is $1: 1.42$, which is close to the theoretical ratio for $\alpha$ $\mathrm{Fe}_{2} \mathrm{O}_{3}$, which is $1: 1.5$. For comparison, the XPS spectra of unanodized steel are shown in Figures S5-S7.

The Raman spectra for the steel anodized for various times are shown in Figure 5. For the steel anodized for 15, 30, and 45 min, broad peaks are seen at 350,534, and $670 \mathrm{~cm}^{-1}$ with a small shoulder at $700 \mathrm{~cm}^{-1}$. These peaks could correspond to magnetite or maghemite. ${ }^{32,33}$ For the longer anodization times (more than $60 \mathrm{~min}$ ), peaks at 223, 289, 402, 491, 605, 658, and $1304 \mathrm{~cm}^{-1}$ are observed which all correspond to $\alpha-\mathrm{Fe}_{2} \mathrm{O}_{3}{ }^{31}$ This confirms the findings of the XPS analysis.

Although only the anode was of our interest, notably, formation of a gray deposit was observed on the cathode during the anodization process. The SEM images of this deposit are shown in Figure 6. It can be seen that the deposit on the cathode consisted of cubic particles typically ranging from 100 to $300 \mathrm{~nm}$ in size. EDX was used to determine the elemental composition of the deposit, which is shown in the Figure S8. The EDX analysis showed that the particles consisted only of Fe. This deposit of metallic Fe on the steel cathode surface is most likely due to the reduction of the dissolved ferrate species as a part of the anodization process.

The proposed reactions at the anode and cathode, respectively, are shown below

$$
\begin{gathered}
\text { anode: } \mathrm{Fe}^{0}+3 \mathrm{~h}^{+} \rightarrow \mathrm{Fe}^{3+}\left(\mathrm{Fe}_{2} \mathrm{O}_{3}\right) \\
\mathrm{Fe}^{3+}+3 \mathrm{~h}^{+} \rightarrow \mathrm{Fe}^{6+}\left(\mathrm{FeO}_{4}^{2-}\right) \\
4 \mathrm{OH}^{-}+4 \mathrm{~h}^{+} \rightarrow 2 \mathrm{H}_{2} \mathrm{O}+\mathrm{O}_{2} \\
\text { cathode: } \mathrm{Fe}^{6+}\left(\mathrm{FeO}_{4}^{2-}\right)+6 \mathrm{e}^{-} \rightarrow \mathrm{Fe}^{0} \\
2 \mathrm{H}_{2} \mathrm{O}+4 \mathrm{e}^{-} \rightarrow \mathrm{H}_{2}+2 \mathrm{OH}^{-}
\end{gathered}
$$

Electrochemical Characterization. The performance of the nanostructured steel was electrochemically tested to determine its suitability for supercapacitor application. Cyclic voltammetry of the plain and nanostructured steel (anodized for $15,30,45,60,120,180$, and $240 \mathrm{~min}$ ) was carried out in a three-electrode configuration in $1 \mathrm{M} \mathrm{NaOH}$ using the steel as the working electrode and $\mathrm{Ag} \mid \mathrm{AgCll} 3 \mathrm{M} \mathrm{KCl}$ and $\mathrm{Pt}$ as the reference and counter electrode, respectively. A series of cyclic voltammograms are shown in Figure 7, which were recorded at a scan rate of $200 \mathrm{mV} / \mathrm{s}$. A close observation of CVs of the steel strips anodized for different times between the window of $0-45$ min reveals two anodic peaks at -0.4 and $0 \mathrm{~V}$. At potentials more positive than $+0.4 \mathrm{~V}$, the rapid increase in anodic current is due to the oxygen evolution reaction. According to the literature, the anodic peak at $-0.4 \mathrm{~V}$ corresponds to the formation of $\mathrm{Fe}(\mathrm{OH})_{2}$ and the anodic peak at $0 \mathrm{~V}$ corresponds to the formation of $\mathrm{Fe}$ (III) oxyhydroxide $(\mathrm{FeOOH}) .{ }^{34}$ The reduction peak at $-0.05 \mathrm{~V}$ corresponds to the reduction of $\mathrm{FeOOH}$ to $\mathrm{Fe}(\mathrm{OH})_{2}$, and the rising cathodic current at around $-0.4 \mathrm{~V}$ probably corresponds to the reduction of $\mathrm{Fe}(\mathrm{OH})_{2}$ to 

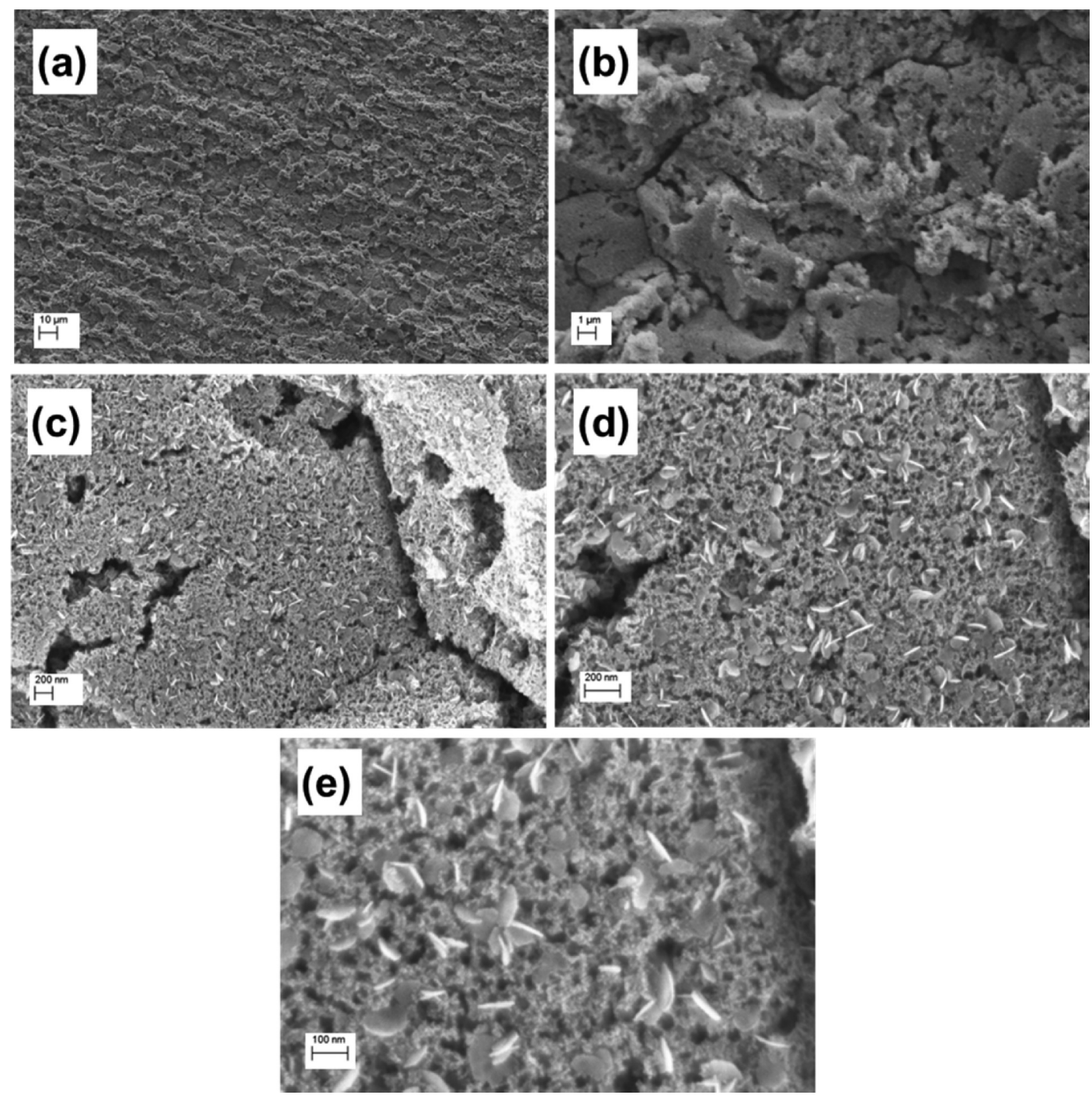

Figure 2. SEM images of nanostructured steel that has been anodized for $240 \mathrm{~min}$ at various magnifications of (a) 1k X, (b) 10k X, (c) 50k X, (d) $100 \mathrm{k} \mathrm{X}$, and (e) $200 \mathrm{k} \mathrm{X}$.

metallic Fe, ${ }^{34}$ although the potential is not scanned sufficiently negative to observe the peak cathodic current. The study also proposes that the second anodic peak (at $0 \mathrm{~V}$ ) could also correspond for the direct conversion of metallic $\mathrm{Fe}$ to $\mathrm{FeOOH}$, which could be a separate pathway opposed to the sequential mechanism. As the steel anodization time is increased further from 45 to $180 \mathrm{~min}$, there is a clear and systematic increase in both anodic and cathodic current, which could be due to the increase in surface area and hence double layer capacitance. This could also correspond to an increase in pseudocapacitative processes such as the oxidation of metallic Fe. Also, as the $1 \mathrm{M}$ $\mathrm{NaOH}$ aqueous electrolyte was not deaerated prior to the capacitance measurements, there is a likelihood that a proportion of cathodic current could also be accounted for the reduction of dissolved oxygen, which also occurs in the same potential range. Anodizing for longer than $180 \mathrm{~min}$ showed a decrease in both anodic and cathodic currents. This could be due to a reduction in the surface area caused by further dissolution of nanostructured $\mathrm{Fe}_{2} \mathrm{O}_{3}$ in the form of ferrate ions as discussed in the previous section.

Also, from the shape of the CVs, it can be seen that the majority of the pseudocapacitance occurs in the negative potential range. For this reason, the anodized steel would be more suitable for application in an asymmetric supercapacitor rather than a symmetric one, where it could be used as the negative electrode and be coupled with a suitable positive electrode material, such as $\mathrm{Mn}_{3} \mathrm{O}_{4}$ or $\mathrm{CoMnO}_{4} \cdot{ }^{35,36}$

Electrochemical impedance spectroscopy (EIS) of the electrodes was conducted under open circuit potential conditions; the Nyquist plots can be seen for various anodization times in Figure 8. For a supercapacitor, the more vertical the line (phase angle of $90^{\circ}$ ) in the Nyquist plot, the more ideal its capacitive behavior. From the lower frequency range of the Nyquist plots, it can be seen that near vertical lines are observed for anodization times ranging from 0 to $120 \mathrm{~min}$, whereas further increase of anodization times to 180 and 240 min has shown less ideal capacitive behavior at lower frequency, as illustrated in Figure 8 by their significant deviation from vertical line behavior. It can be seen that there is a general trend of the angle of the vertical line with respect to the real axis, as it seems to decrease with the longer anodization times. The presence of a $45^{\circ}$ line at the higher frequencies is indicative of transmission line behavior which is due to diffusion of the electrolyte ions through the porous structure of the electrode. The transmission line behavior seems to extend to lower frequencies with longer anodization times, further confirming 


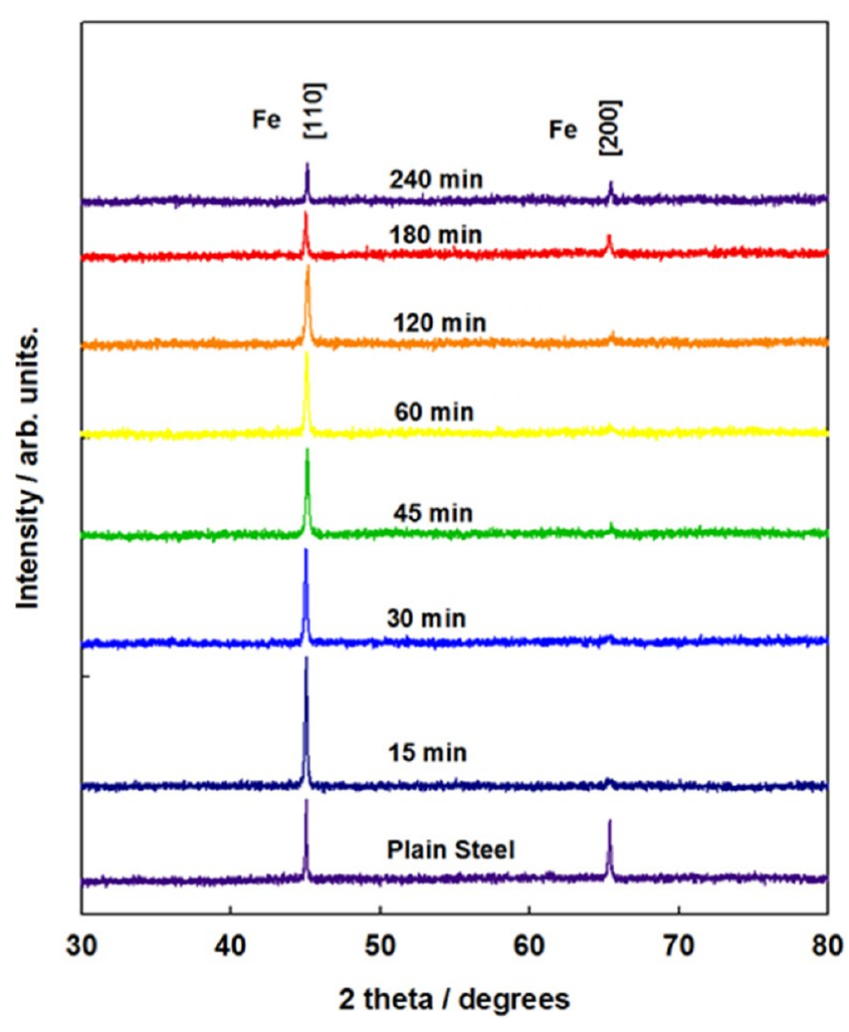

Figure 3. XRD patterns of steel anodized for various times.
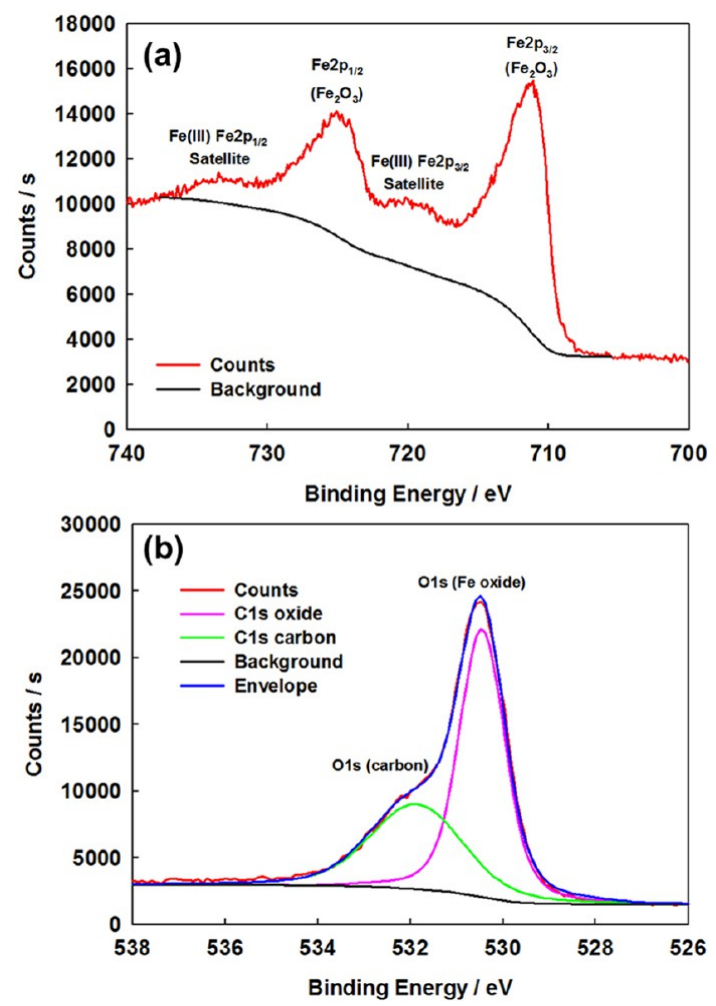

Figure 4. XPS spectrum of $240 \mathrm{~min}$ anodized steel sample showing the (a) $\mathrm{Fe}$ and (b) $\mathrm{O}$ regions.

that the electrodes with longer anodization times have a higher diffusion resistance due to higher surface area. The value of the high-frequency real axis intercept is known as the solution resistance. It can be seen that all electrodes exhibit solution
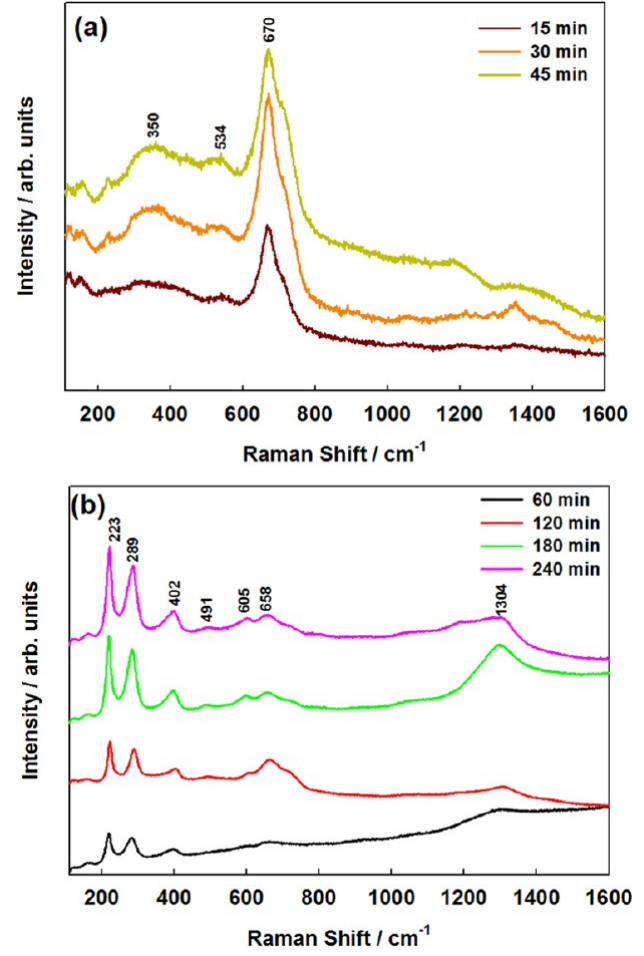

Figure 5. Raman spectra of (a) 15, 30, and 45 min anodized steel; (b) $60,120,180$, and 240 min anodized steel.

resistances of around $2 \Omega$, regardless of the length of the anodization time. This could indicate that the anodization time (i.e., electrode texture) does not significantly affect the conductivity of the electrode. This could be linked to the fact that the electrode surface in all cases is $\mathrm{Fe}_{2} \mathrm{O}_{3}$, as evident by XPS.

Transmission line behavior is due to "semi-infinite diffusion" of the electrolyte in to the porous structure. ${ }^{37}$ This results in a $45^{\circ}$ line in the Nyquist plot and this effect is typically seen at high frequency domain when the penetration depth of the electrolyte is shorter than the diffusion length. In other words, at high frequencies (shorter time scales), the pores are only being partially filled by the electrolyte. When the frequency is gradually lowered (longer time scale), the $45^{\circ}$ line becomes more vertical, indicating that the penetration depth of the electrolyte has exceeded the diffusion length. Under these conditions, the pore is being fully charged and then fully discharged upon the AC perturbation. In the ideal circumstance in which all pores are uniform and identical, a $90^{\circ}$ line should be seen, indicating that all pores are being charged simultaneously, i.e., synchronous charging. ${ }^{38}$ However, in reality, in the system being studied in our case, the pore sizes are nonuniform and there is a distribution of pore sizes-this results in asynchronous charging. ${ }^{38}$ Therefore, even at low frequencies, there is a line that has a non- $90^{\circ}$ phase angle, which implies that although some pores are being completely charged, some, still, are not. This is why the angles deviate more from $90^{\circ}$ with longer anodization times. There are more pores to be filled, because of higher surface area, and there is more likely a larger distribution of pore sizes.

A plot of the phase angles of all samples as a function of Log frequency is shown in Figure 9. The closer the phase angle approaches to $90^{\circ}$, the more the device behaves like an ideal capacitor; it is more ideal if the phase angle approaches $90^{\circ}$ at 

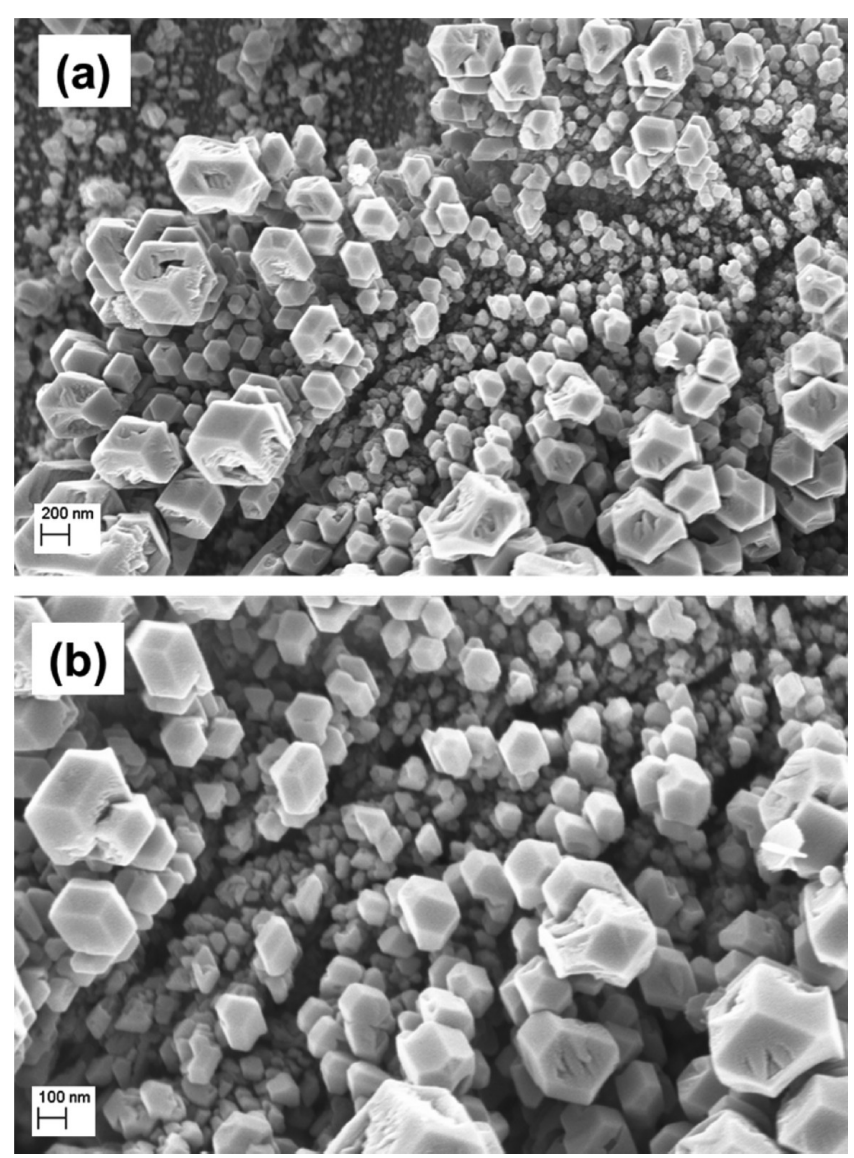

Figure 6. SEM images at magnifications of (a) $50 \mathrm{kX}$ and (b) $100 \mathrm{kX}$, to show the morphology of the material coated on the cathode during the anodization process (this image corresponds to the $240 \mathrm{~min}$ anodization process).

higher frequencies. There seems to be no particular trend in the phase angle at low frequencies of $0.01 \mathrm{~Hz}$, with the values averaging around $80^{\circ}$ for anodization times between 0 to 120 min; however, it decreased to just above $60^{\circ}$ for anodization times of 180 and $240 \mathrm{~min}$. At higher frequencies (at around 10 $\mathrm{Hz}$ ), a more clear trend in the phase angle can be identified. Generally, as the anodization time increases, the frequency at which the phase angle reaches an asymptotic value decreases.
Practically, this means that the pores are being charged more efficiently at lower anodization times compared to that of the longer anodization times.

As the Nyquist plot showed near-vertical line capacitive behavior, a simplified series-RC circuit model was used to simulate the capacitive and resistive elements of the supercapacitor. In this model, the resistance is the real part of the impedance spectrum, and the capacitance is determined using the equation $C=-1 /\left(2 \pi f Z^{\prime \prime}\right)$, where $f$ is the frequency in $\mathrm{Hz}$ and $Z^{\prime \prime}$ is the imaginary part of the impedance spectrum. The overall capacitance as a function of frequency is shown in Figure 10, and the overall capacitance at low frequency (0.01 $\mathrm{Hz}$ ) as a function of the anodization time is shown in Figure 11. It can be seen that the capacitance increased from 0.00012 to $18 \mathrm{mF} \mathrm{cm}^{-2}$ when the anodization time was increased from 0 to $180 \mathrm{~min}$, respectively. For a longer anodization time of 240 $\mathrm{min}$, the capacitance drops to $13.5 \mathrm{mF} \mathrm{cm}^{-2}$, most likely due to a reduction in the surface area due to collapse in the nanostructure due to extensive dissolution of $\mathrm{Fe}_{2} \mathrm{O}_{3}$. This reduction in surface area was also confirmed by a similar trend in the CVs.

The imaginary component of the capacitance can be separated from the real component in order to determine the time constant of the electrochemical system. The imaginary capacitance as a function of frequency is shown in Figure 12. The maximum of the imaginary component of the capacitance can be used to determine the relaxation time constant, $\tau_{0}$, which is the minimum time required to discharge all the energy from the device with an efficiency of greater than $50 \%$ of its maximum value; this value is used as a factor of merit for supercapacitors.

$$
\tau_{0}=\frac{1}{f_{\max }}
$$

The trend of the time constant with the anodization time is shown in Figure 13. The time constant for plain (unanodized) steel is $0.12 \mathrm{~ms}$, which then increased by a factor of 10 , to 1.2 $\mathrm{ms}$ just by anodizing it for $15 \mathrm{~min}$. The time constant increased linearly to around $25 \mathrm{~ms}$ as the anodization time is further increased to $60 \mathrm{~min}$. Beyond this point, there is a sharp increase in the time constant to $80 \mathrm{~ms}$ for the electrode anodized for $120 \mathrm{~min}$. This nonlinear behavior indicates that charging takes increasingly longer for longer anodization times. The time
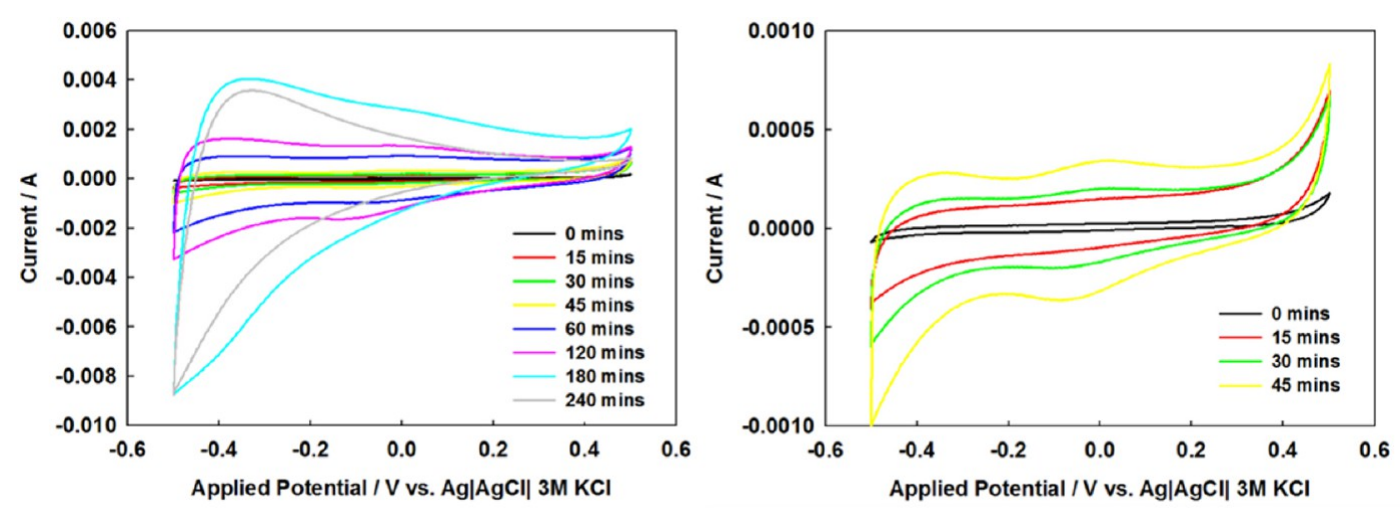

Figure 7. Cyclic voltammograms of nanostructured steel which has been anodized for various times ranging from 0 to $240 \mathrm{~min}$ (left) and 0 to $45 \mathrm{~min}$ (right, shown at a lower current range for clarity). Measurements were conducted in a standard three-electrode electrochemical cell in $1 \mathrm{M} \mathrm{NaOH}$ using steel as the working electrode and $\mathrm{Ag} / \mathrm{AgCl} 3 \mathrm{M} \mathrm{KCl}$ and $\mathrm{Pt}$ as the reference and counter electrode, respectively. Scan rate is maintained at 200 $\mathrm{mV} / \mathrm{s}$. 

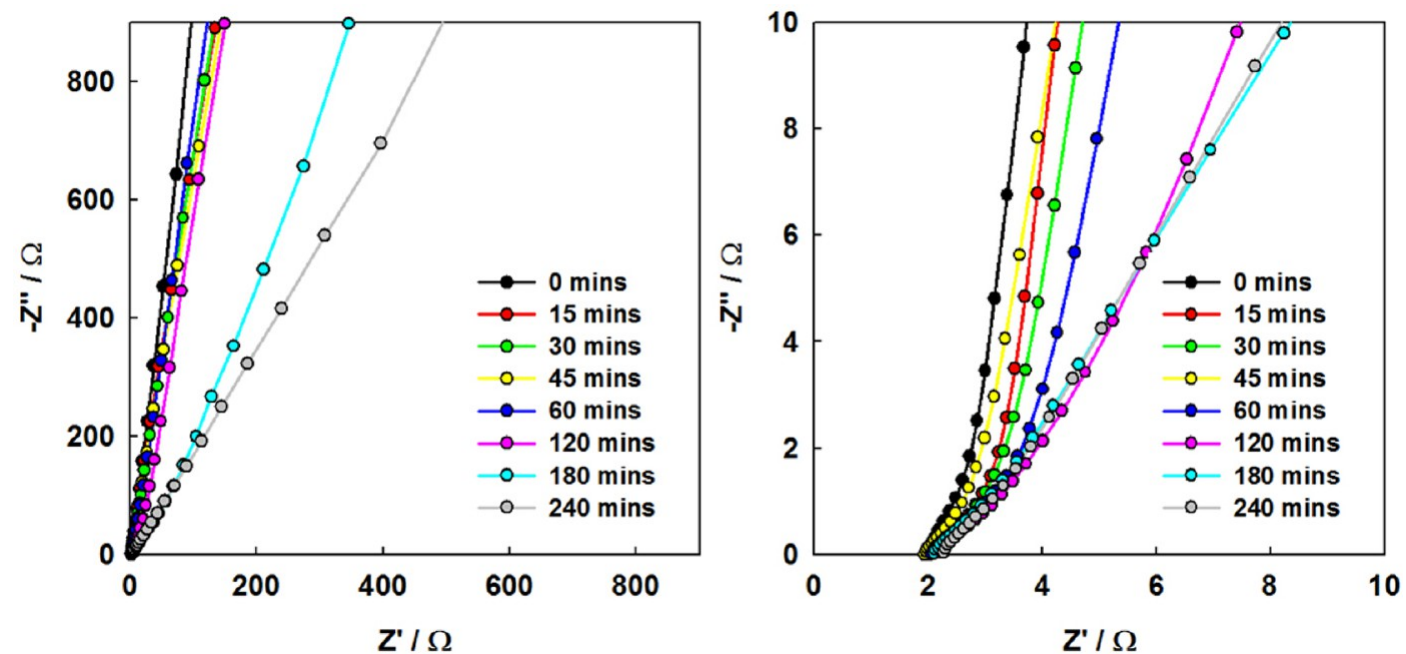

Figure 8. Nyquist plots of nanostructured steel by anodization at various times ranging from $0-240$ min (left). The graph on the right shows an expanded Nyquist plot in the high-frequency region.

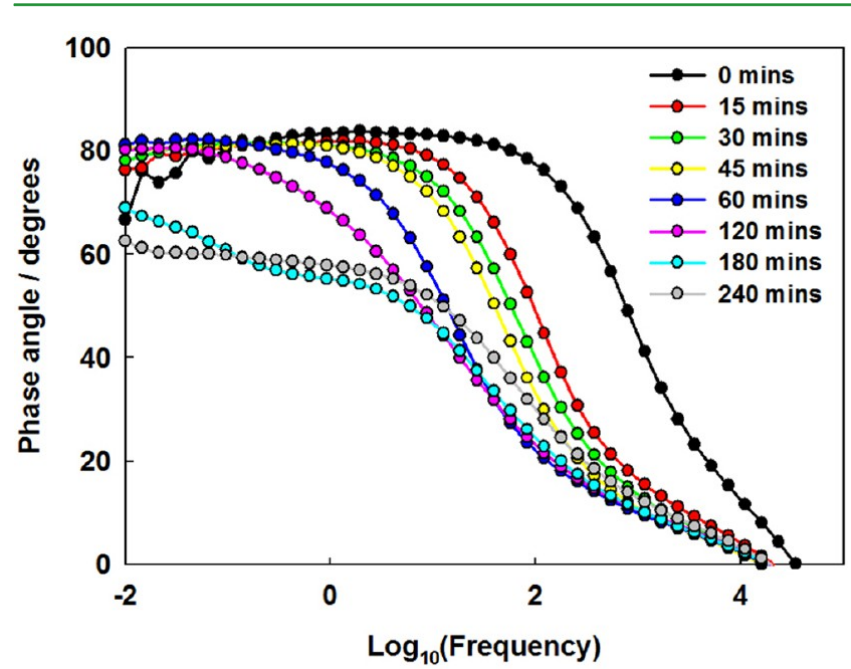

Figure 9. Plot of phase angle as a function of log frequency for nanostructured steel anodized for various times ranging from 0 to 240 $\min$.

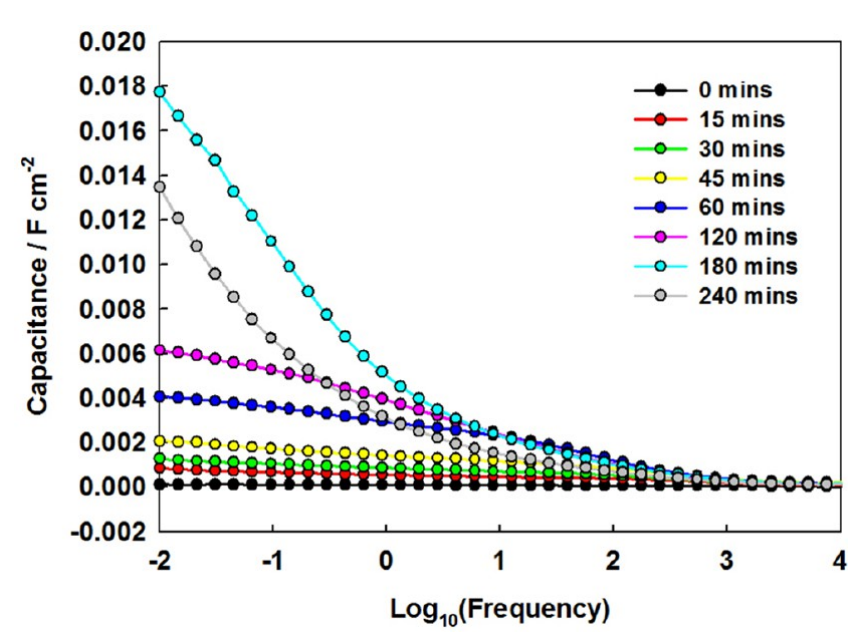

Figure 10. Capacitance as a function of log frequency for nanostructured steel anodized for various times ranging from 0 to $240 \mathrm{~min}$.

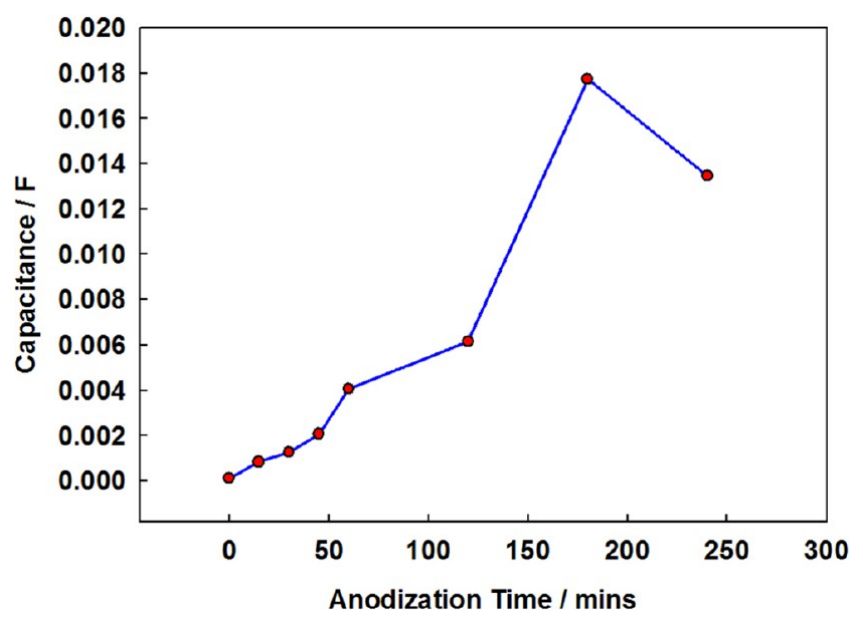

Figure 11. Capacitance as a function of the anodization time of nanostructured steel at low frequency $(0.01 \mathrm{~Hz})$.

constant is not calculable for 180 and 240 min because of the absence of maxima within the frequency range scanned in each case. This suggests that the time constant must have increased beyond $100 \mathrm{~s}$, an indication of the presence of pores deep in the nanostructure, which takes a long time for the electrolyte to penetrate.

The stability of the 240 min anodized steel sample was tested in $1 \mathrm{M} \mathrm{NaOH}$ for 10000 cycles as shown in Figure 14. The data show that the anodized steel shows no signs of degradation after 10000 cycles, which shows that the pseudocapacitive processes taking place on the electrode surface are highly reversible. In fact, the capacitance seems to increase with the cycle number.

\section{CONCLUSIONS}

It has been demonstrated that anodization is an effective way of nanostructuring steel in order to make high surface area electrodes for use in supercapacitors. It was found that the anodization process produced nanostructures because of two main processes: (1) oxidation of metallic $\mathrm{Fe}$ to $\mathrm{Fe}(\mathrm{III})$, which was confirmed to be $\mathrm{Fe}_{2} \mathrm{O}_{3}$ by XPS; and (2) dissolution of $\mathrm{Fe}_{2} \mathrm{O}_{3}$ by further oxidation of $\mathrm{Fe}$ (III) to $\mathrm{Fe}(\mathrm{VI})$, the ferrate ion, which was soluble in in the electrolyte $(10 \mathrm{M} \mathrm{NaOH})$ until it 

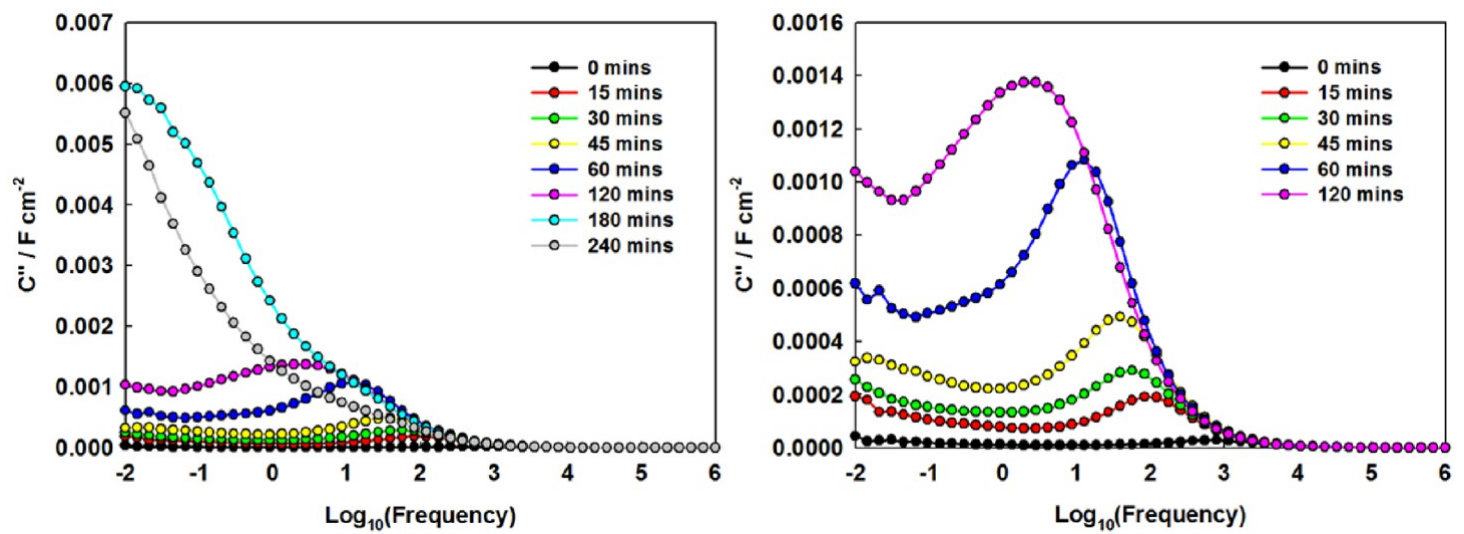

Figure 12. Imaginary component of the capacitance as a function of $\log _{10}$ frequency for nanostructured steel anodized for various times ranging from 0-240 min (left). The graph on the right shows only the 0-120 min anodization for clarity. The maxima can be used to determine the time constants $\left(\tau=1 / f_{\max }\right)$.

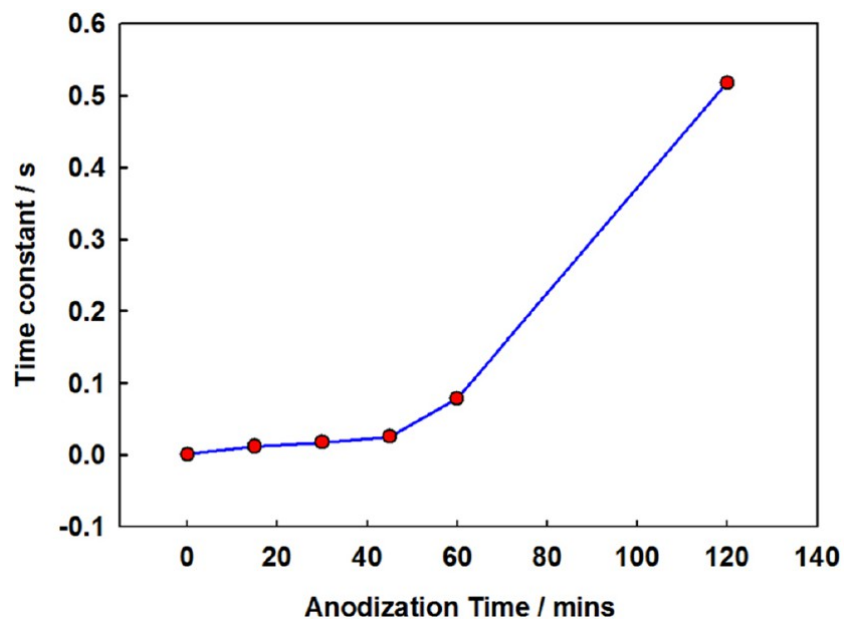

Figure 13. Trend of the time constant as a function of the anodization time of the nanostructured steel.

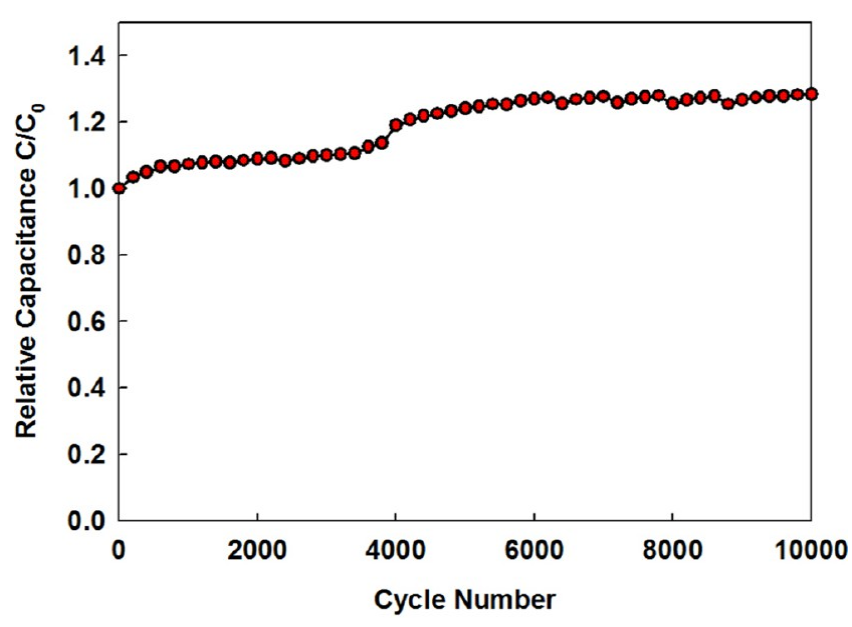

Figure 14. Stability test of $240 \mathrm{~min}$ anodized steel sample.

eventually precipitated out as $\mathrm{Fe}$ (III) either in the oxide or hydroxide form due to the unstable nature of the ferrate ion. The steel was anodized for various times, ranging from 0 to 240 min. An upper limit for the time of anodization was set at 240 min due to longer anodization resulting in crumbling of the nanostructure and delamination from the steel. These anodized electrodes were then tested for application as electrodes in supercapacitors. Three-electrode cyclic voltammetry in $1 \mathrm{M}$ $\mathrm{NaOH}$ showed that the pseuodocapacitive current originates from the oxidation of metallic $\mathrm{Fe}$ to $\mathrm{Fe}(\mathrm{OH})_{2}$ and then further oxidation to $\mathrm{FeOOH}$, and the respective reduction of these species back to metallic Fe. These redox processes were found to be remarkably reversible as stability testing showed no decline in the capacitance after 10000 cycles. The capacitance in $1 \mathrm{M} \mathrm{NaOH}$ was found to be $18 \mathrm{mF} \mathrm{cm}^{-2}$. The anodized steel electrodes are suitable for application as the negative electrode in an asymmetric supercapacitor.

\section{ASSOCIATED CONTENT}

\section{Supporting Information}

The Supporting Information is available free of charge on the ACS Publications website at DOI: 10.1021/acsami.5b12107.

$$
\text { Additional figures (PDF) }
$$

\section{AUTHOR INFORMATION}

\section{Corresponding Author}

*E-mail: U.Wijayantha@lboro.ac.uk.

\section{Notes}

The authors declare no competing financial interest.

\section{ACKNOWLEDGMENTS}

J.S. thanks Loughborough University and Tata Steel for the $\mathrm{PhD}$ studentship to conduct this work. All authors acknowledge the support given by members of the energy research lab (ERL) at the Department of Chemistry, Loughborough University. KGUW would like to acknowledge the support received from RCUK to conduct this research.

\section{REFERENCES}

(1) Nguyen, V. H.; Shim, J.-J. Three-Dimensional Nickel foam/ graphene/NiCo2O4 as High-Performance Electrodes for Supercapacitors. J. Power Sources 2015, 273, 110-117.

(2) Harrison, D.; Qiu, F.; Fyson, J.; Xu, Y.; Evans, P.; Southee, D. A Coaxial Single Fibre Supercapacitor for Energy Storage. Phys. Chem. Chem. Phys. 2013, 15 (29), 12215-12219.

(3) Shinde, S. K.; Dubal, D. P.; Ghodake, G. S.; Fulari, V. J. Hierarchical 3D-Flower-like $\mathrm{CuO}$ Nanostructure on Copper Foil for Supercapacitors. RSC Adv. 2015, 5 (6), 4443-4447.

(4) Zhao, F.; Vicenzo, A.; Hashempour, M.; Bestetti, M. Supercapacitor Electrodes by Direct Growth of Multi-Walled Carbon 
Nanotubes on Al: A Study of Performance versus Layer Growth Evolution. Electrochim. Acta 2014, 150, 35-45.

(5) Fan, H.; Zhao, N.; Wang, H.; Xu, J.; Pan, F. 3D Conductive Network-Based Free-Standing PANI-RGO-MWNTs Hybrid Film for High-Performance Flexible Supercapacitor. J. Mater. Chem. A 2014, 2 (31), 12340-12347.

(6) Grote, F.; Kühnel, R.-S.; Balducci, A.; Lei, Y. Template Assisted Fabrication of Free-Standing MnO2 Nanotube and Nanowire Arrays and Their Application in Supercapacitors. Appl. Phys. Lett. 2014, 104, 053904.

(7) Guo, W.-H.; Liu, T.-J.; Jiang, P.; Zhang, Z.-J. Free-Standing Porous Manganese Dioxide/graphene Composite Films for High Performance Supercapacitors. J. Colloid Interface Sci. 2015, 437, 304310.

(8) Hassan, M.; Reddy, K. R.; Haque, E.; Faisal, S. N.; Ghasemi, S.; Minett, A. I.; Gomes, V. G. Hierarchical Assembly of Graphene/ polyaniline Nanostructures to Synthesize Free-Standing Supercapacitor Electrode. Compos. Sci. Technol. 2014, 98, 1-8.

(9) Yu, P.; Zhao, X.; Huang, Z.; Li, Y.; Zhang, Q. Free-Standing Three-Dimensional Graphene and Polyaniline Nanowire Arrays Hybrid Foams for High-Performance Flexible and Lightweight Supercapacitors. J. Mater. Chem. A 2014, 2 (35), 14413-14420.

(10) Simon, P.; Gogotsi, Y. Materials for Electrochemical Capacitors. Nat. Mater. 2008, 7 (11), 845-854.

(11) Masuda, H.; Fukuda, K. Ordered Metal Nanohole Arrays Made by a Two-Step Replication of Honeycomb Structures of Anodic Alumina. Science 1995, 268 (5216), 1466-1468.

(12) Zwilling, V.; Aucouturier, M.; Darque-Ceretti, E. Anodic Oxidation of Titanium and TA6V Alloy in Chromic Media. An Electrochemical Approach. Electrochim. Acta 1999, 45 (6), 921-929.

(13) Tsuchiya, H.; Schmuki, P. Self-Organized High Aspect Ratio Porous Hafnium Oxide Prepared by Electrochemical Anodization. Electrochem. Commun. 2005, 7 (1), 49-52.

(14) Ravanbakhsh, A.; Rashchi, F.; Sohi, M. H.; Nekouei, R. K. Synthesis of Nanostructured Zinc Oxide Thin Films by Anodic Oxidation Method. Adv. Mater. Res. 2014, 829, 347-351.

(15) Yang, L.; Qian, L.; Tian, X.; Li, J.; Dai, J.; Guo, Y.; Xiao, D. Hierarchically Porous Nickel Oxide Nanosheets Grown on Nickel Foam Prepared by One-Step in Situ Anodization for High-Performance Supercapacitors. Chem. - Asian J. 2014, 9 (6), 1579-1585.

(16) Norlin, A.; Pan, J.; Leygraf, C. Fabrication of Porous Nb2O5 by Plasma Electrolysis Anodization and Electrochemical Characterization of the Oxide. J. Electrochem. Soc. 2006, 153 (7), B225-B230.

(17) Mukherjee, N.; Paulose, M.; Varghese, O. K.; Mor, G. K.; Grimes, C. A. Fabrication of Nanoporous Tungsten Oxide by Galvanostatic Anodization. J. Mater. Res. 2003, 18 (10), 2296-2299.

(18) Rangaraju, R. R; Raja, K. S.; Panday, A.; Misra, M. An Investigation on Room Temperature Synthesis of Vertically Oriented Arrays of Iron Oxide Nanotubes by Anodization of Iron. Electrochim. Acta 2010, 55 (3), 785-793.

(19) Xie, K.; Guo, M.; Huang, H.; Liu, Y. Fabrication of Iron Oxide Nanotube Arrays by Electrochemical Anodization. Corros. Sci. 2014, $88,66-75$.

(20) Zhang, Z.; Hossain, M. F.; Takahashi, T. Fabrication of ShapeControlled A-Fe2O3 Nanostructures by Sonoelectrochemical Anodization for Visible Light Photocatalytic Application. Mater. Lett. 2010, 64 (3), 435-438.

(21) Chang, C.-Y.; Wang, C.-H.; Tseng, C.-J.; Cheng, K.-W.; Hourng, L.-W.; Tsai, B.-T. Self-Oriented Iron Oxide Nanorod Array Thin Film for Photoelectrochemical Hydrogen Production. Int. J. Hydrogen Energy 2012, 37 (18), 13616-13622.

(22) Prakasam, H. E.; Varghese, O. K.; Paulose, M.; Mor, G. K.; Grimes, C. A. Synthesis and Photoelectrochemical Properties of Nanoporous Iron (III) Oxide by Potentiostatic Anodization. Nanotechnology 2006, 17 (17), 4285-4291.

(23) Konno, Y.; Tsuji, E.; Skeldon, P.; Thompson, G. E.; Habazaki, H. Factors Influencing the Growth Behaviour of Nanoporous Anodic Films on Iron under Galvanostatic Anodizing. J. Solid State Electrochem. 2012, 16 (12), 3887-3896.
(24) Mohapatra, S. K.; John, S. E.; Banerjee, S.; Misra, M. Water Photooxidation by Smooth and Ultrathin A-Fe 2 O 3 Nanotube Arrays. Chem. Mater. 2009, 21 (14), 3048-3055.

(25) Zhan, W.; Ni, H.; Chen, R.; Song, X.; Huo, K.; Fu, J. Formation of Nanopore Arrays on Stainless Steel Surface by Anodization for Visible-Light Photocatalytic Degradation of Organic Pollutants. J. Mater. Res. 2012, 27 (18), 2417-2424.

(26) Burleigh, T. D.; Dotson, T. C.; Dotson, K. T.; Gabay, S. J.; Sloan, T. B.; Ferrell, S. G. Anodizing Steel in $\mathrm{KOH}$ and $\mathrm{NaOH}$ Solutions. J. Electrochem. Soc. 2007, 154 (10), C579-C586.

(27) Beverskog, B.; Puigdomenech, I. Revised Pourbaix Diagrams for Iron at $25-300{ }^{\circ}$ C. Corros. Sci. 1996, 38 (12), 2121-2135.

(28) Audette, R. J.; Quail, J. W.; Smith, P. J. Ferrate (VI) Ion, a Novel Oxidizing Agent. Tetrahedron Lett. 1971, 12 (3), 279-282.

(29) Jiang, J.-Q.; Lloyd, B. Progress in the Development and Use of ferrate(VI) Salt as an Oxidant and Coagulant for Water and Wastewater Treatment. Water Res. 2002, 36 (6), 1397-1408.

(30) Bergeron, R. J.; Brittenham, G. M. The Development of Iron Chelators for Clinical Use; CRC Press: Boca Raton, FL, 1993.

(31) Tahir, A. A.; Wijayantha, K. G. U.; Saremi-Yarahmadi, S.; Mazhar, M.; McKee, V. Nanostructured A-Fe 2 O 3 Thin Films for Photoelectrochemical Hydrogen Generation. Chem. Mater. 2009, 21 (16), 3763-3772.

(32) Colomban, P.; Cherifi, S.; Despert, G. Raman Identification of Corrosion Products on Automotive Galvanized Steel Sheets. J. Raman Spectrosc. 2008, 39 (7), 881-886.

(33) Neff, D.; Bellot-Gurlet, L.; Dillmann, P.; Reguer, S.; Legrand, L. Raman Imaging of Ancient Rust Scales on Archaeological Iron Artefacts for Long-Term Atmospheric Corrosion Mechanisms Study. J. Raman Spectrosc. 2006, 37 (10), 1228-1237.

(34) MacDonald, D. D.; Roberts, B. The Cyclic Voltammetry of Carbon Steel in Concentrated Sodium Hydroxide Solution. Electrochim. Acta 1978, 23 (8), 781-786.

(35) Guan, C.; Liu, J.; Wang, Y.; Mao, L.; Fan, Z.; Shen, Z.; Zhang, H.; Wang, J. Iron Oxide-Decorated Carbon for Supercapacitor Anodes with Ultrahigh Energy Density and Outstanding Cycling Stability. ACS Nano 2015, 9 (5), 5198-5207.

(36) Hu, Y.; Guan, C.; Feng, G.; Ke, Q.; Huang, X.; Wang, J. Flexible Asymmetric Supercapacitor Based on Structure-Optimized Mn 3 O 4 /Reduced Graphene Oxide Nanohybrid Paper with High Energy and Power Density. Adv. Funct. Mater. 2015, 25 (47), 7291-7299.

(37) Song, J.; Bazant, M. Z. Effects of Nanoparticle Geometry and Size Distribution on Diffusion Impedance of Battery Electrodes. J. Electrochem. Soc. 2013, 160 (1), A15-A24.

(38) Fletcher, S.; Black, V. J.; Kirkpatrick, I. A Universal Equivalent Circuit for Carbon-Based Supercapacitors. J. Solid State Electrochem. 2014, 18 (5), 1377-1387. 